\title{
Arranjo Produtivo Local e as Agroindústrias Familiares da Região das Missões: Lógicas Diferentes?
}

\author{
Carlos Eduardo Ruschel Anes \\ Universidade Federal da Fronteira Sul \\ Cidonea Machado Deponti \\ Universidade de Santa Cruz do Sul \\ Silvio Cezar Arend \\ Universidade de Santa Cruz do Sul
}

\begin{abstract}
Resumo
Na região do Corede Missões, as agroindústrias familiares se constituíram com apoio do setor público e de instituições com as quais se relacionam e desenvolvem suas atividades produtivas. Desde o ano de 2014, a região das Missões vem executando o Plano de Desenvolvimento do Arranjo Produtivo Local da Agroindústria Familiar, que, na sua essência, tem origem teórica e histórica na teoria econômica neoclássica, que reproduz a lógica da economia industrial. Com isso em vista, o propósito deste estudo foi analisar como a produção das agroindústrias familiares, na região das Missões, é influenciada pela lógica industrial do conceito de Arranjo Produtivo Local. $\mathrm{O}$ alcance desse propósito foi por meio de pesquisa de campo, fundamentado por referencial teórico sobre arranjos produtivos locais e agroindústria familiar. Identificou-se que a atividade produtiva é, predominantemente, artesanal. A lógica da economia de escala, intrínseca ao modelo teórico do Arranjo Produtivo Local, não consegue estabelecer uma relação com a dinâmica produtiva das agroindústrias familiares, pois estas apresentam baixa produção, ausência de divisão do trabalho e especialização. Dessa forma, a tentativa de industrialização retira a essência da atividade familiar, pela qual as famílias produzem seus produtos em ambiente em que não há predomínio da técnica sobre o saber-fazer. $\mathrm{A}$ intenção é de que este estudo possa servir como uma interpretação que vai além do conceito de Arranjo Produtivo Local e, ao mesmo tempo, sirva como base para construção ou aperfeiçoamento de políticas públicas que contemplem melhor a realidade da produção das agroindústrias familiares.
\end{abstract}

Palavras-chave: Arranjo Produtivo Local. Agroindústrias Familiares. Lógica Industrial. Produção Artesanal. 


\title{
Local Productive Arrangement and the Family Agroindustries of the Region of Missões: Different Logics?
}

\begin{abstract}
In the region of Corede Missões, family agroindustries were constituted with the support of the public sector and institutions with which they relate and develop their productive activities. Since the year 2014, the region of Missões has been implementing the Local Productive Arrangement Development Plan of the Family Agroindustry, which, in essence, has a theoretical and historical origin in neoclassical economic theory, which reproduces the logic of the industrial economy. With this in view, the purpose of this study was to analyze how the production of family agroindustries in the region of Missões is influenced by the industrial logic of the concept of Local Productive Arrangement. We reached our objective through field research, that was based on theoretical reference on local productive arrangements and family agroindustry. We identified that the productive activity is, mainly, artisan. The logic of economies of scale, intrinsic to the theoretical model of APL, cannot establish a relation with the productive dynamics of family agroindustries, since they have low production, absence of division of labor and specialization. Thus, the attempt of industrialization takes away the essence of family activity by which families produce their products in an environment where there is no predominance of technique over know-how. The intention is that this study can serve as an interpretation that goes beyond the concept of Local Productive Arrangement (APL) and, at the same time, serves as a basis for the construction or improvement of public policies that better contemplate the reality of the production of family agroindustries.
\end{abstract}

Keywords: Local Productive Arrangement. Family Agroindustries. Industrial Logic. Artisan Production.

\section{Arreglo Productivo Local y las Agroindustrias Familiares de la Región de las Missões: Lógicas Diferentes?}

\section{Resumen}

En la región del Corede Missões, las agroindustrias familiares se constituyeron con apoyo del sector público y de instituciones con las que se relacionan y desarrollan sus actividades productivas. Desde el año 2014 la región de las Misiones viene ejecutando el Plan de Desarrollo del Arreglo Productivo Local de la Agroindustria Familiar en las Missões, que, en su esencia, tiene origen teórico e histórico en la teoría económica neoclásica, que reproduce la lógica de la economía industrial. Con esto en vista, el propósito de este estudio fue analizar cómo la producción de las agroindustrias familiares, en la región de las Misiones, es influenciada por la lógica industrial del 
concepto de Arreglo Productivo Local. El alcance de este propósito fue por medio de investigación de campo, fundamentado por referencial teórico sobre arreglos productivos locales y agroindustria familiar. Se identificó que la actividad productiva es, predominantemente, artesanal. La lógica de la economía de escala, intrínseca al modelo teórico del APL, no logra establecer una relación con la dinámica productiva de las agroindustrias familiares, pues éstas presentan baja producción, ausencia de división del trabajo y especialización. De esta forma, el intento de industrialización retira la esencia de la actividad familiar, por la cual las familias producen sus productos en ambiente en que no hay predominio de la técnica sobre los saberes. La intención es que este estudio pueda servir como una interpretación que va más allá del concepto de Arreglo Productivo Local (APL) y, al mismo tiempo, sirva como base para la construcción o perfeccionamiento de políticas públicas, que contemplen mejor la realidad de la producción de las agroindustrias familia.

Palabras clave: Arreglo Productivo Local. Agroindustrias Familiares. Lógica Industrial. Producción Artesanal.

\section{INTRODUÇÃO}

As agroindústrias familiares estão presentes em diversas regiões e produzem, por meio do trabalho familiar, produtos que atendem a parte da demanda regional por alimentos. Na região do Corede Missões, localizada no Estado do Rio Grande do Sul, existem agroindústrias familiares que apresentam uma dinâmica produtiva que ajuda na compreensão das particularidades da região.

O propósito deste estudo foi analisar como a produção das agroindústrias familiares, na região das Missões, é influenciada pela lógica industrial do conceito de Arranjo Produtivo Local - APL. Na seção 2, é apresentada a revisão sobre o conceito de Arranjo Produtivo Local, sua lógica econômica, origem, características e relação com outras noções de aglomerações produtivas. $\mathrm{Na}$ sequência, a seção 3 aborda um debate teórico sobre as agroindústrias familiares, por meio de uma revisão teórica com várias interpretações.

Os resultados são descritos na seção 5 , que aborda as contradições entre a dinâmica produtiva das agroindústrias familiares das Missões e o modelo teórico de APL. A última seção tem as considerações finais do estudo. 


\section{O ARRANJO PRODUTIVO LOCAL E SEU REDUCIONISMO ECONÔMICO}

Existem vários conceitos para explicar as organizações produtivas de um território. Essas distinções conceituais, segundo Suzigan et al (2004), surgem na literatura como resultado de pesquisas sobre a dinâmica produtiva, a interação, as articulações e as interações entre atores regionais.

As aglomerações de empresas, segundo Marshall (1982), necessitam de recursos naturais numa dada região e das condições de infraestrutura para sua funcionalidade econômica.

Os recursos naturais sustentam os insumos necessários para a produção, enquanto que a infraestrutura está relacionada à logística de distribuição e comunicação com outras localidades. A logística é importante, pois, para o desenvolvimento econômico da região, é necessária a comercialização com mercados não só regionais, mas externos (COSTA, 2012).

As concepções teóricas acerca das aglomerações produtivas ajudam a compreender como a dinâmica produtiva se transforma ao longo do tempo em diversas regiões. Essas aglomerações se constituem pela proximidade espacial de agentes econômicos, sociais e políticos. Nessa perspectiva, Cassiolato e Lastres (1999) observam que a proximidade entre esses agentes favorece o acesso aos insumos necessários à produção e à comercialização de produtos dentro da lógica econômica. A busca pela otimização de resultados leva o aglomerado a obter vantagem competitiva no mercado. Nessa lógica, micro e pequenos empreendimentos podem aumentar suas chances de sobrevivência e crescimento, tornando-se cada vez mais competitivos no mercado.

As aglomerações produtivas podem ser interpretadas, segundo Cassiolato e Lastres (1999), como Distritos Industriais, como Clusters, como Cadeias Produtivas e como APLs. O Distrito Industrial, segundo Becattini (1999), possui sua origem nos estudos de Marshall sobre a organização industrial na Inglaterra. A partir desses estudos, o distrito industrial passou a ser entendido como um conceito que congrega uma comunidade de recursos humanos e instituições em determinado espaço geográfico. Esse aglomerado envolve várias empresas, com elevado grau de especialização e interdependência, seja de caráter horizontal (clientes, tecnologias, etc.) ou vertical (comprador/fornecedor). A proximidade é fator chave para concentração dos insumos, da mão de obra, da tecnologia e da inovação utilizados para a produção de produtos com alto valor agregado para consumo local e, principalmente, atender à demanda externa.

Os Clusters como aglomerados produtivos são formados por um conjunto de empresas que apresentam naturezas produtivas similares e complementares. Em alguns casos, esse tipo de aglomeração dá mais ênfase ao aspecto concorrencial em detrimento do aspecto cooperativo, como fator preponderante na dinâmica interativa entre os empreendimentos que participam. O foco direciona-se para os empreendimentos e não a outros atores, como instituições 
de ensino, pesquisa e desenvolvimento, suporte técnico, fomento, esfera pública, etc (CASSIOLATO e LASTRES, 1999).

Segundo Porter (1990), os clusters são concentrações geográficas de instituições produtivas que se inter-relacionam em setores econômicos similares e complementares. A especialização é imprescindível para obtenção da eficiência produtiva do aglomerado. Parcerias estratégicas são realizadas com o objetivo de maior volume e qualidade nos produtos produzidos e, consequentemente, maior ganho e competitividade no mercado. Esse modelo se manifesta sob a lógica instrumental utilitarista e competitiva da economia de mercado.

Outra interpretação acerca de aglomerações produtivas se manifesta no conceito de cadeia produtiva. Para Cassiolato e Lastres (1999), a cadeia ocorre a partir do encadeamento de empreendimentos organizados num processo consecutivo pelo qual insumos são transformados e movimentados nas etapas de produção, de distribuição e de comercialização de bens e de serviços. A divisão do trabalho se materializa em cada nó (empreendimento) participante da cadeia, organizando o trabalho de cada uma das etapas do processo de transformação e/ou movimentação de produto ou serviços. Além disso, não há necessidade de as empresas participantes estarem numa mesma região ou localidade.

O conceito de cadeia produtiva se consolidou paralelamente ao conceito de agribusiness a partir dos estudos de Davis e Goldberg (1957) e Goldberg (1968) nos Estados Unidos e, no conceito de filière aplicado ao estudo da organização agroindustrial na França (ZYLBERSZTAJN e NEVES, 2000).

Ao lado do conceito de agribusiness, surgiu o conceito de Commoditie System Aproach - CSA, derivado da Teoria Econômica Neoclássica. Sua concepção foi desenvolvida a partir de estudos da cadeia do trigo, da soja e da laranja na Flórida, EUA. Esse conceito traduz uma sequência de operações específicas desde a produção de insumos, processamento e distribuição de um produto. A lógica da economia industrial dentro desse modelo sistematizado inclui o mercado de insumos agrícolas, a produção agrícola, operações de estocagem, processamento, atacado e varejo (ZYLBERSZTAJN e NEVES, 2000).

Outro conceito é o de filière, também conhecido como "cadeias". Tem como origem estudos realizados na escola de Economia Industrial Francesa. Esse conceito compreende a sequência de operações de concepção de um produto, realizada em várias instituições interdependentes e complementares, visando à maximização dos seus lucros (ZYLBERSZTAJN e NEVES, 2000).

Dessa forma, a Economia Neoclássica dá base à origem do conceito de Cadeias Produtivas, ou seja, a lógica da economia industrial envolve a produção em cadeia sempre buscando a otimização dos recursos e dos resultados.

O conceito de APL surge a partir de diferentes experiências. Ao longo do tempo, o conceito foi se transformando e passou a indicar também experiências em vários lugares do mundo. Ele se espalhou como um referencial para o 
desenvolvimento econômico, sendo necessário encontrar experiências que pudessem ser caracterizadas como APL ou, no mínimo, como APL potencial.

O APL, segundo Cassiolato e Lastres (1999), procura congregar agentes econômicos, políticos e sociais em um espaço regional. Seu foco está em um conjunto específico de atividades econômicas, que apresentam relações diretas ou mesmo incipientes. Há, nessa aglomeração, uma interação e uma participação de empresas, desde produtoras de bens e serviços finais até fornecedoras de insumos e máquinas, prestadoras de serviços, comércio, clientes, etc. e suas diversas formas de associação, cooperação e representação.

As organizações públicas e privadas voltadas à formação e à capacitação de recursos humanos, como escolas técnicas e universidades; instituições de pesquisa, desenvolvimento e engenharia; entidades políticas, de promoção e de fomento, também são atores que participam de um APL. Como sinônimo do conceito de APL, surge a denominação Sistema Produtivo Local, em que os vínculos passam a ser mais consistentes e com capacidade de gerar e de propagar o caráter inovador endógeno, da competitividade e do desenvolvimento local (CASSIOLATO e LASTRES, 1999).

Essas interpretações mostram o APL como uma concentração geográfica de empresas e de instituições que se relacionam em determinados setores produtivos e serviços. Apesar de existirem concepções divergentes sobre o que sejam APLs, há convergência sobre o entendimento que eles sejam aglomerações de empresas e de instituições públicas e privadas que podem se organizar e interagir em diferentes setores produtivos.

O desenvolvimento de um APL, segundo Brandão, Costa e Alves (2006), necessita de uma participação ativa do Estado. Daí o papel das instituições públicas como atores importantes nos projetos de desenvolvimento de APLs. Para Suzigan (2004), a participação pública é fundamental para o desenvolvimento de um APL no que se refere à sua sustentabilidade; ao seu capital social; ao acesso à educação, à saúde, ao crédito, aos centros de pesquisa, aos serviços empresariais e à infraestrutura logística; à mobilização dos recursos endógenos; à articulação de recursos públicos ou privados; à atração de recursos externos e à conexão com mercados.

O aumento da capacidade produtiva, bem como a competitividade das empresas, é o propósito principal no processo de formação e de desenvolvimento do APL. O foco está na redução dos custos e na produção em escala (IGLIORI, 2001).

Outro elemento, segundo Matos (2004), que justifica os APLs é a facilitação no processo de transferência e de acumulação de conhecimento entre os empreendimentos locais. Essas informações disseminadas passam a qualificar o processo decisório de investimentos, tanto na visão de novas oportunidades de mercado e novos produtos como também em novos processos produtivos. Há, ainda, uma redução de custos nas transferências de informações em decorrência da proximidade geográfica dos atores envolvidos. 
A proximidade física e tecnológica entre os atores favorece o processo de inovação produtiva. Além disso, as informações podem ocorrer de maneira formal (parcerias formalizadas) e de maneira informal (reuniões entre trabalhadores/empreendedores).

O conceito de APL, suas origens e a relação com outros conceitos de aglomerações produtivas expressam, em sua essência, seu reducionismo econômico. A lógica da economia industrial é incorporada pelo modelo de APL em diferentes setores produtivos, inclusive na agricultura.

Assim, para uma reflexão mais aprofundada sobre a possibilidade ou não do modelo de APL ser incorporado à dinâmica produtiva familiar, torna-se importante a compreensão das origens e transformações da agricultura familiar ao longo do tempo, tema que é abordado na próxima seção.

\section{A AGROINDUSTRIALIZAÇÃO FAMILIAR: INTERPRETAÇÕES TEÓRICAS}

As transformações da agricultura familiar permitiram o desenvolvimento da noção de agroindústria familiar. Para essa compreensão, o debate teórico vem sendo feito, em nível de Brasil, desde os anos 1990, considerando várias atividades familiares de agroindustrialização, interpretadas como agroindústrias familiares.

Wilkinson (2002), ao interpretar a agroindústria familiar, apresenta como base teórica a Sociologia Econômica e a Teoria das Convenções, que ajudam na compreensão do funcionamento dos mercados que atendem às atividades familiares de agroindustrialização.

Essas atividades, desenvolvidas por pequenos empreendimentos agroindustriais, acabam gerando mercados com base na proximidade, que considera as relações familiares e os canais de comercialização com os clientes em uma localidade. A confiança entre produtores e consumidores, o saber-fazer, as relações de parentesco e vizinhança dão base para mercados, tanto formais quanto informais (WILKINSON, 2002).

Para Wilkinson (2002), a imersão (embeddedness) vem garantindo ao longo do tempo a sustentação das agroindústrias na vida social local, mas essas atividades estão sofrendo cada vez mais a pressão de outros mercados e lógicas por meio de imposições de normas principalmente ligadas aos aspectos higiênicos e sanitários. Se isso se materializar, assegura o autor, as agroindústrias familiares podem entrar num processo de inclusão ("critérios" para existir) e de exclusão (inconformidade com "critérios") nas diversas áreas rurais brasileiras.

Para Mior (2005), o surgimento das agroindústrias rurais pode ser observado como uma reconfiguração do produto colonial produzido pela agricultura familiar. Essa transformação ocorreu por meio de associações de 
produtores com apoio do poder público. O produto colonial processado pelas agroindústrias passou a ser visto, pelos produtores, como um produto de maior valor e com possibilidade de gerar maior renda para as famílias.

Outros aspectos corroboram para a caracterização da agroindústria familiar rural. Aspectos relacionados à localização no meio rural, às máquinas e aos equipamentos utilizados em menor escala, à matéria-prima própria ou vinda de vizinhos, à produção artesanal e ao trabalho realizado pelos próprios membros familiares. Além disso, essa dinâmica também pode se manifestar por meio de empreendimentos associativos que reúnem várias famílias produtoras (MIOR, 2005).

Dois pontos são fundamentais, segundo Mior (2005), para a sustentação dos empreendimentos agroindustriais familiares: 1) a horizontalidade das redes sociais que produtores estabelecem com atores, instituições e consumidores locais e, 2) a utilização do saber-fazer que está contido na cultura regional.

Esses dois pontos são importantes no momento em que as relações horizontais e o saber-fazer sejam materializados nos produtos das agroindústrias, não somente como agregação de valor monetário, mas o valor cultural expresso nos produtos que permite a diferenciação em relação a outros mercados, principalmente com relação à identidade artesanal, colonial e agroecológica (MIOR, 2005).

Para Mior (2005), a Agroindústria Familiar vem da Agricultura Familiar, submetendo parte da produção vegetal e animal e produtos processados, visando maior valor de comercialização e/ou troca. Esclarece ainda que, para se constituir uma Agroindústria Familiar, tem de ser de uma família, de uma associação ou de uma rede de associações/cooperativas familiares; produzir sua matéria-prima ou adquirir em pequena quantidade de agricultores vizinhos; com predomínio de mão de obra familiar e apresentar laços de parentesco e sanguíneo ao longo de gerações.

Com a ênfase mais voltada a noções de sistemas agroalimentares, Maluf (2004) se insere nesse debate teórico quando interpreta que as atividades de agregação de valor ao produto primário podem se caracterizar como uma complementaridade à produção primária na propriedade familiar. Além desse complemento, as atividades agroalimentares são essenciais para a reprodução social digna das famílias, por gerarem renda e por possibilitarem o autoconsumo.

Além disso, as agroindústrias podem ser compreendidas com base no enfoque territorial, o qual agrega três pontos: a identidade territorial dos produtores; a proximidade da produção e do consumo e a abordagem espacial do território como aglomeração de unidades produtivas (cluster) (MALUF, 2004).

O primeiro ponto ligado à identidade territorial dos produtores é exemplificado pela denominação de origem e selos regionais que visam a identificar no produto aspectos culturais característicos da região. O segundo ponto está ligado à facilitação das transações por meio das vantagens 
relacionadas aos baixos custos de transporte, à qualidade e à confiança dos consumidores nos produtos. Já o terceiro ponto considera as vantagens no aproveitamento dos recursos específicos, como a mão de obra, a produção própria de matérias-primas, a criação e inovação local e o conhecimento adquirido socializado entre os produtores (MALUF, 2004).

A razão de ser das agroindústrias, segundo Maluf (2004), é a oportunidade de poder produzir suas próprias matérias-primas e utilizarem no processo de agroindustrialização familiar, tanto de maneira individual como coletiva, gerando maior autonomia e diferenciação social e econômica aos produtores.

Em outra interpretação, apresentada por Prezotto (2002), a Agroindústria Familiar ajuda na retomada dos saberes sociais das unidades de produção familiar no que se refere ao beneficiamento de alimentos que, ao longo do tempo, sempre existiu nas propriedades rurais e que foi gradativamente desconstruído pelo modelo de modernização da agricultura.

Segundo Prezotto (2002), alguns aspectos ajudam a compreender a Agroindústria Familiar. No que tange à sua estrutura, ela está locada na propriedade do agricultor. A matéria-prima utilizada vem dos produtos de origem animal e/ou vegetal da própria propriedade e as atividades laborais são, predominantemente, dos membros familiares.

Em pesquisa realizada com agroindústrias familiares do norte do Estado do Rio Grande do Sul, Gazolla (2009) verificou que 45,30\% dos produtores pesquisados informaram que a matéria-prima é totalmente produzida na propriedade rural. Esse é um ponto importante no sentido de que quanto maior a utilização da matéria-prima produzida na propriedade da família, menor será sua dependência em relação aos fornecedores. Assim, essa dinâmica permite às agroindústrias familiares maior autonomia frente ao mercado fornecedor e consequente redução dos custos de processamento.

Nesse sentido, Nierdele e Wesz Junior (2009) interpretam que a agroindustrialização familiar está sendo associada à autonomia das famílias produtoras. Isso se justifica pelo domínio dos recursos utilizados como suprimentos básicos para a produção da agroindústria. Assim, com o domínio da própria produção das matérias-primas, os produtores acabam não precisando adquiri-las no mercado fornecedor.

A agroindústria familiar representa o processamento de produtos primários do próprio agricultor. A forma de produção ocorre de maneira artesanal com escala de produção não industrial em instalações físicas gerenciadas pela própria família produtora (PREZOTTO, 2001).

A escala de produção da agroindústria familiar está diretamente ligada à capacidade de produção dos produtos agropecuários da propriedade e da capacidade de trabalho dos integrantes da família produtora. A família estabelece a manutenção ou ampliação da atividade, bem como atende à legislação, partindo da própria família. Assim, estabelecem-se alternativas endógenas de domínio e 
controle do que é produzido, ou seja, mantém-se a lógica camponesa, mas também se acrescentam aspectos empresariais no momento que assume princípios de gestão e de comercialização com o mercado (PREZOTTO, 2002).

Diante disso, Prezotto (2002, p. 8), formula sua interpretação com relação às agroindústrias familiares: "a agroindustrialização é o beneficiamento dos produtos agropecuários (secagem, classificação, limpeza) e/ou a transformação de matérias-primas gerando novos produtos, de origem animal ou vegetal".

A agroindústria familiar também é estudada quanto às suas denominações. É o caso de Guimarães e Silveira (2010) que descrevem e denominam a "agroindústria caseira" que se caracteriza por manter sua base produtiva artesanal, que se direciona ao autoconsumo da família produtora e pouca relação com mercados, ou seja, comercializam apenas quando há excedente, portanto, não estabelecem um compromisso com o atendimento da demanda do mercado.

A "agroindústria familiar artesanal" é denominada e interpretada por Guimarães e Silveira (2010), como uma agroindústria que mantém o caráter artesanal nos seus produtos. O saber é passado de geração para geração, mas admitem o aprimoramento técnico por meio de cursos e de trocas de experiências que são aplicadas e incorporadas na produção por meio das Boas Práticas de Fabricação - BPF. Há uma preocupação com a manutenção da identidade territorial do produto e, ao mesmo tempo, com a qualidade ligada ao atendimento à legislação sanitária.

A outra denominação que Guimarães e Silveira (2010) utilizam é "agroindústria familiar de pequeno porte". A interpretação acerca dessa denominação, segundo os autores, caracteriza-se por uma atividade produtiva como negócio integrado aos mercados, com utilização de tecnologias externas e adequação às normas legais para a funcionalidade dos seus processos produtivos. A produção não é artesanal e, consequentemente, seus produtos não se diferenciam dos produtos industriais comercializados no mercado.

Na experiência estudada na região do Médio e Alto Uruguai do Estado do Rio Grande do Sul pelos pesquisadores Gelson Pelegrini e Marcio Gazolla, surge outra interpretação acerca do debate sobre as agroindústrias familiares. Segundo Pelegrini e Gazolla (2008), a agroindústria familiar passa a ser uma estratégia de reprodução social, pois materializa atividades e oportunidades de agregação de valor na produção das famílias rurais, gerando receitas e complementando rendas, além de oferecer empregos aqueles produtores que optam pelas atividades de transformação das matérias-primas que já produzem.

Com essas considerações e interpretações teóricas sobre a agroindústria familiar, sustenta-se a presença da lógica produtiva camponesa, mas, por outro lado, apresenta aspectos empresariais que, de certa maneira, caracterizam-se pela comercialização dos produtos no mercado. Com isso, a afirmação de Bartra (2009) esclarece que a concepção industrial não encontra sustentação na maneira de produzir familiar. Assim, a Agroindústria Familiar baseada na 
Agricultura Familiar pode manter uma relação com a organização produtiva sob a lógica camponesa, mas estabelecendo relações sociais e econômicas que também se manifestam na lógica empresarial.

\section{A PRODUÇÃO NAS AGROINDÚSTRIAS FAMILIARES DAS MISSÕES E O MODELO DE ARRANJO PRODUTIVO LOCAL}

$\mathrm{Na}$ pesquisa de campo, foram entrevistados 14 proprietários(as) e aplicados 136 questionários aos responsáveis pelas agroindústrias familiares. O período de realização da pesquisa foi de janeiro a junho de 2016. Inicialmente, apresenta-se um breve histórico do processo de formação do APL e os resultados das entrevistas são apresentados a seguir por meio da descrição de como a produção das agroindústrias familiares, na região das Missões, é influenciada pela lógica industrial do conceito de APL.

O APL é uma forma de aglomeração que procura organizar agentes econômicos, políticos e sociais localizados no território. O propósito dessa união é potencializar a capacidade de geração e de propagação do caráter inovador endógeno da competitividade e do crescimento local (CASSIOLATO e LASTRES, 1999).

Por volta dos anos 2000, começaram as discussões sobre o desenvolvimento do APL nas Missões. Algumas representações e organizações como associações, cooperativas, movimentos sociais, universidades e órgãos de Governo iniciaram debates sobre a possibilidade da formalização de um APL da agroindústria familiar na região.

Em 2011, esses atores concentraram seus esforços na formalização do APL, no sentido de enquadrá-lo no projeto de fortalecimento dos APLs do Rio Grande do Sul. O propósito estava no incentivo e valorização das agroindústrias familiares da região missioneira.

A primeira etapa, ocorrida em 2013, foi a realização de um diagnóstico das agroindústrias familiares nas Missões. Nessa etapa, foi necessária a definição da técnica de coleta e de análise de dados, a relação das fontes de consulta utilizadas, o plano de trabalho e o cronograma físico, a identificação dos principais agentes participantes da elaboração do Plano de Desenvolvimento, escolha das instituições-chave para governança, agenda de reuniões com identificação dos participantes e um esboço da estrutura do plano para cumprimento da referida etapa.

$\mathrm{Na}$ segunda etapa, foi caracterizado o APL. Essa fase foi dividida em contextualização do arranjo; governança e cooperação; desenvolvimento de tecnologia e inovações; desenvolvimento sustentável; formação profissional e possibilidade local de capacitação; projetos atuais de investimento e fontes de financiamento; infraestrutura e logística; níveis de qualidade e controle do 
processo produtivo; mapeamento da cadeia produtiva e da cadeia de valor e canal de distribuição para os mercados interno e externo. Além disso, no ano de 2014, foi realizado seminário para validação e entrega do relatório completo da governança do APL para a Agência Gaúcha de Desenvolvimento e Promoção do Investimento - AGDI.

A definição de estratégias e de objetivos foi realizada na terceira etapa do plano. Nessa etapa, foi necessária a formalização de uma visão compartilhada entre os atores envolvidos sobre o desenvolvimento econômico, social, ambiental e regional do APL numa perspectiva mínima de cinco anos. As estratégias foram fragmentadas em grupos temáticos e organizadas por meio de ações de curto, médio e longo prazo. Foram, ainda, definidos indicadores para avaliar o resultado de cada ação.

Com isso, a intenção dos atores regionais, motivados pela política de incentivo aos APLs do Estado do Rio Grande do Sul, foi a de incorporar a lógica da economia industrial na dinâmica produtiva das agroindústrias familiares da região das Missões. Nesse sentido e ao encontro da interpretação de Igliori (2001), o propósito era fortificar a capacidade produtiva e competitiva das agroindústrias familiares, contribuindo para minimização dos custos e aumento da escala produtiva. Assim, o modelo de APL começava a ser incorporado nas agroindústrias familiares da região.

Com o passar do tempo, as ações começaram a ser executadas pelos atores regionais, com o objetivo de formalização de todas as agroindústrias familiares da região. Nessas ações, começaram a surgir alguns problemas e resistências por parte das famílias produtoras, principalmente na dificuldade em absorver o "pacote" de informações e exigências estabelecidas pelo APL e pela legislação.

Em 2016, o Plano de Desenvolvimento do APL Missões completou três anos e muitas agroindústrias ainda estavam em processo de formalização. Outras não se formalizaram e estão produzindo e comercializando seus produtos à margem da legislação vigente. Segundo esta pesquisa, as dificuldades encontradas pelos produtores são os custos de adequação física e dos processos produtivos da agroindústria.

As agroindústrias se tornaram a principal renda das famílias produtoras, agregando valor aos produtos primários, produzindo de maneira, predominantemente, artesanal. A lógica da economia de escala, nesse sentido, não abarca essa dinâmica porque as famílias produtoras somente conseguiriam aumentar sua produção com a incorporação de mão de obra e de tecnologia de produção, adequação ao excesso de exigências da legislação e realização de investimentos em infraestrutura física e capacitação técnica. Essa é uma contradição que se constatou entre a concepção de APL e a dinâmica produtiva das agroindústrias familiares da região.

Essa constatação se justifica a partir do aprofundamento e do detalhamento das relações sociais e econômicas que se manifestam na dinâmica 
produtiva das agroindústrias familiares. A maneira como se manifestam as relações com os fornecedores, com as atividades produtivas e com o consumidor ajudam a sustentar a tese de que a lógica da economia industrial do conceito de APL não abarca a dinâmica produtiva familiar.

A origem da força de trabalho e a organização das atividades na dinâmica produtiva das agroindústrias familiares se manifestam de maneira contrária à lógica do conceito de APL. Enquanto nas agroindústrias o trabalho é realizado pelos próprios membros da família, na lógica industrial do APL, a agroindústria deve estabelecer uma relação integrada com o mercado de mão de obra. Essa contradição, além de se manifestar no trabalho realizado nas agroindústrias familiares, também está no inciso II da Lei $n^{\circ}$ 11.326/2006, que define agricultura familiar. Ela diz que a produção familiar se caracteriza pela utilização de mão de obra, predominantemente, "[...] da própria família nas atividades econômicas do seu estabelecimento ou empreendimento". O constatado na pesquisa é que as agroindústrias familiares possuem, na sua base, a agricultura familiar, de onde vem a maior parte das suas matérias-primas e utilizam predominantemente a mão de obra da família.

As atividades de gestão, de produção, de troca mercantil ou não mercantil, segundo Prezotto (2001), são realizadas pelos membros do núcleo familiar. Com isso, as atividades realizadas nas agroindústrias familiares estão, predominantemente, sob a responsabilidade da família.

A outra contradição se manifesta na organização do trabalho. Nas agroindústrias familiares, a produção é artesanal, consistido de atividades produtivas organizadas informalmente, sem divisão do trabalho e padrões de desempenho dos trabalhadores. Por outro lado, o APL procura incorporar na produção familiar a divisão do trabalho e a especialização do trabalhador, monitorado por técnicas de avaliação de desempenho e indicadores de produtividade. Os procedimentos operacionais padrão - POPs constantes nos programas de qualidade materializam o detalhamento dessa lógica produtiva fragmentada e complexa, com predomínio da técnica em detrimento do saberfazer.

A manutenção da agroindústria familiar perde espaço com a incorporação da lógica industrial sobre o trabalho familiar. Essa tentativa de industrialização retira a essência da atividade familiar, pela qual as famílias produzem seus produtos em ambiente em que não há predomínio da técnica sobre o saber-fazer.

Nesse sentido, os produtores familiares são alvo de ações de formação técnica. Esse é um dos objetivos do APL, ou seja, incorporar aos conhecimentos adquiridos pelas famílias produtoras instrumentos de planejamento e de controle da produção, sob a ótica industrial. Dessa forma, o APL tenta impor nos eventos de formação de produtores, uma lógica produtiva mecanicista, de escala e de exportação.

A lógica industrial incorporada nos programas de formação dos produtores entra em confronto com o saber-fazer das famílias produtoras. Uma 
tensão entre a produção industrial do APL e a produção artesanal das agroindústrias familiares se materializa. Dessa forma, o saber-fazer adquirido por meio da livre experiência dos membros familiares ao longo do tempo gera uma resistência ao regramento e à normatização dos instrumentos técnicos impostos pelo APL.

Os cursos técnicos, treinamentos e demais eventos de formação técnica também são meios utilizados pelos produtores familiares para adquirirem conhecimento. Os cursos do Serviço Nacional de Aprendizagem Rural - Senar, da Empresa de Assistência Técnica e Extensão Rural - Emater e da Empresa Brasileira de Pesquisa Agropecuária - Embrapa foram citados como importantes para aperfeiçoamento das atividades produtivas e dos produtos da agroindústria. As exigências legais e sanitárias, bem como a gestão da agroindústria, são os principais temas abordados atualmente nesses eventos.

Esse conhecimento passado por meio das ações de formação técnica de produtores aborda temas que, muitas vezes, encontram resistência por parte das famílias produtoras. Dessa forma, muitas das agroindústrias acabam não se legalizando em decorrência do excesso de transformações físicas e mudanças exigidas, mas há um propósito claro de induzir as famílias produtoras a se adequarem às normas da indústria, na lógica industrial. Nessas ações de formação, predominam temas relacionados à lógica industrial, em detrimento da preocupação com a manutenção de atividades produtivas que proporcionem mais autonomia às agroindústrias familiares. O meio utilizado para isso são cursos de formação técnica, sem considerar as particularidades da dinâmica produtiva familiar, que é de natureza não industrial.

Esse é um problema diretamente ligado às políticas públicas e à legislação atual que, por meio das instituições de formação técnica, tentam transferir para os produtores a lógica do conceito de APL, totalmente instrumental, como se fosse um processo de desvalorização do saber-fazer das famílias produtoras.

A resistência dos produtores com relação ao conhecimento transmitido em cursos de formação técnica se manifesta. Muitos produtores não aceitam normas e determinações impostas por modelos de produção e gestão que não levem em consideração suas realidades. Para Deponti (2010, p. 194), a realidade dos produtores “[...] não se restringe às opções espaciais e estratégicas promovidas por determinados projetos ou planos vindos de fora".

Os produtores se posicionam, divergem e reagem quando percebem que as formas de dominação estão incorporadas a programas de capacitação. À perda da autonomia e da dignidade, quando ameaçada, os produtores reagem de maneira contrária, posicionando-se por meio do silêncio ou por meio de argumentos divergentes aos dos técnicos em eventos de formação (DEPONTI, 2010).

Essas são formas de manifestação dos produtores quando da utilização de métodos de abordagem vindos de instituições públicas e/ou privadas, que tentam 
impor formas de gestão e produção sem considerar as demandas e a realidade dos produtores.

A formação híbrida do conhecimento dos produtores é base para posicionamentos contrários aos modelos que divergem das suas concepções e saberes adquiridos ao longo da sua vida. Segundo interpretação de Deponti (2010, p. 205), “[...] o conhecimento é um híbrido, fruto da apropriação e da transformação, apresentando uma heterogeneidade de manifestações, e uma combinação de elementos naturais, sociais e técnicos. O conhecimento é construído heterogeneamente".

Dessa forma, os produtores não podem ser vistos como sujeitos passivos às imposições do plano de desenvolvimento do APL das agroindústrias familiares das Missões. O "pacote" industrial é claro e está na essência do conceito e no conteúdo das ações de vários atores regionais.

O argumento de que a industrialização da produção familiar vai garantir maior rentabilidade às famílias é utilizado por vários atores regionais que defendem o plano do APL voltado à economia industrial. Esse argumento destaca o aumento da rentabilidade das famílias produtoras, mas desconsidera a perda de autonomia no trabalho e do conhecimento do saber-fazer, transmitido de geração a geração entre membros familiares.

Além disso, as agroindústrias se transformariam em complexos econômicos agroindustriais, com o objetivo da produção em escala para obterem vantagens cada vez maiores no mercado competitivo. O resultado disso gera redução ou extinção da produção familiar e concentração da produção em poucas agroindústrias. Assim, a questão social pode sofrer um impacto, pois o número de famílias produtoras pode passar a ser cada vez menor no meio rural. 0 trabalho deixa de acontecer no ambiente familiar e passa a se desenvolver em um ambiente empresarial em que os trabalhadores não são mais os próprios membros da família.

Com isso, a política de incentivo à criação de APLs de agroindústrias familiares, por ser política importante para as agroindústrias familiares, deve ser aperfeiçoada com informações que consideram a realidade da dinâmica produtiva das famílias produtoras da região. Essa preocupação é relevante, pois retira a abordagem de APL como "modelo" de desenvolvimento produtivo e coloca as características produtivas familiares no foco principal. Assim, essa política de incentivo às agroindústrias familiares pode oportunizar um desenvolvimento produtivo, mais equitativo e com maior inclusão social.

Na relação com os fornecedores, verifica-se outra contradição do modelo de APL aplicado na agroindústria familiar. As principais matérias-primas utilizadas nas agroindústrias familiares vêm da produção primária da própria família, como é o caso do leite que é transformado em produtos derivados; a cana-de-açúcar que é transformada em produtos com valor agregado maior e os hortifrutigranjeiros que são transformados em geleias, doces e conservas. Todos esses produtos utilizam como principal matéria-prima produtos primários produzidos na 
propriedade da própria família. Dessa forma, as famílias produtoras são mais autônomas em relação ao mercado fornecedor na dinâmica produtiva das agroindústrias familiares.

Segundo Prezotto (2001), essa lógica da agroindústria familiar não é industrial. A contradição começa na dinâmica produtiva, com a utilização da matéria-prima produzida pela própria família, em sua propriedade rural. Pode haver eventualmente a necessidade de obtenção de algum insumo produzido por outras famílias localizadas nas proximidades, mas isso não predomina da dinâmica produtiva das agroindústrias familiares.

Por outro lado, a lógica por trás do conceito de APL procura incentivar os produtores a fazer parcerias com fornecedores de suprimentos. Nessa lógica, as matérias-primas, bem como componentes adquiridos para a produção dos produtos, são, predominantemente, compradas de fornecedores. Com isso, a produção primária da própria família deixa de ser a principal fonte de matériasprimas para a agroindústria.

Para Cassiolato e Lastres (1999), as organizações produtivas que participam do APL devem estar próximas das organizações fornecedoras de insumos, seja de matérias-primas, de componentes, de máquinas e de equipamentos. Dessa forma, asseguram esses autores, as chances de sobrevivência e de crescimento econômico aumentam.

Se para Prezotto (2001) os insumos que abastecem a agroindústria familiar vêm, predominantemente, da própria propriedade da família, Cassiolato e Lastres (1999) entendem que os insumos para as atividades industriais, predominantemente, vêm do mercado fornecedor. Assim, a lógica do APL com relação à aquisição de suprimentos não abarca a relação com os fornecedores manifestada na dinâmica produtiva familiar, pois ao mesmo tempo em que realizam atividades na agroindústria, os membros familiares se envolvem nas atividades de produção primária que ocorrem na propriedade rural.

As atividades de produção são desempenhadas, simultaneamente, na agroindústria familiar e na propriedade da família. A produção familiar se manifesta tanto na produção primária como nas atividades produtivas na agroindústria. A maneira como os produtos são produzidos é, predominantemente, braçal e artesanal, diferente da lógica impressa pela concepção de APL.

O conceito de APL aborda a atividade produtiva como um processo, ou seja, um conjunto de etapas encadeadas, que começa pelos vários fornecedores de suprimentos, passa pelas várias etapas de produção da organização, até o cliente atacadista, varejista e/ou consumidor final. Cada etapa possui seus operadores, com formação e conhecimentos técnicos específicos, que desempenham suas atividades conforme padrão sequencial estabelecido e em ambiente que incentiva a inovação e a utilização de tecnologias de robotização e automação. 
Com isso, a especialização é exigida para atender às atividades produtivas, cada vez mais fragmentadas e sequenciais. Na interpretação de Marshall (1982), a especialização está intrínseca na lógica industrial que orienta para o desenvolvimento de habilidades e de conhecimentos técnicos, alinhados com o avanço tecnológico e aumento da produtividade.

$\mathrm{Na}$ dinâmica produtiva das agroindústrias familiares das Missões, a especialização não se manifesta. Ao contrário, as atividades produtivas não são fragmentadas e a força de trabalho, vinda da família, não é especializada. 0 trabalho é artesanal e todos se ajudam na execução das atividades produtivas.

O APL possui, em seus princípios, a cooperação e participação dos atores regionais, não de forma altruísta, mas a partir de uma lógica instrumental e utilitarista. A intenção da afirmação de Dalla Vecchia (2006) deixa clara a essência do APL: o objetivo principal do APL está na busca por ajustes e soluções que permitam melhorar os resultados econômicos e técnicos nas relações entre os atores locais.

O mercado competitivo, a obtenção de vantagem competitiva, a inovação, a mecanização e a automação, a padronização, a divisão do trabalho, a especialização, a aplicação de ferramentas quantitativas e padronizadas, a produção em escala, a gestão voltada para resultados econômicos e a otimização de recursos são alguns princípios teóricos que vêm na base do argumento, baseado no conceito de APL, de como a produção deve ser pensada.

As tentativas de incorporação dessa lógica industrial estão encontrando resistências na dinâmica produtiva das agroindústrias familiares. A razão para isso está na interpretação de que, de um lado, há uma legislação concebida com base na lógica industrial que tenta regrar atividades produtivas de natureza artesanal. De outro lado, muitos produtores afirmam que, se forem atender a todas as exigências da legislação, não conseguem manter suas agroindústrias. Além disso, a assistência técnica desenvolve seu trabalho no sentido de convencer os produtores familiares a adequarem suas instalações físicas e sua produção à legislação vigente.

Essa tensão se estabelece por não haver, até o momento, uma legislação que consiga compreender a lógica da produção familiar na sua essência. A legislação foi criada sem participação daqueles atores sujeitos a ela. Dessa forma, a resistência se observa nas relações sociais e econômicas da produção familiar, não por teimosia dos produtores ou por custos elevados, mas por uma lógica produtiva familiar ainda não discutida e materializada em lei.

A formalização das agroindústrias familiares na região das Missões vem se desenvolvendo gradativamente ao longo dos anos. A dificuldade de a produção familiar ser legalizada é visível, pois há resistência dos produtores em se adequarem às normas estabelecidas pela legislação. A lógica que predomina entre os produtores em relação à legalização é a possibilidade de comercialização local e regional e não às mudanças e transformações exigidas em sua maneira de produzir. Assim, criou-se uma tese equivocada de que, para comercializar os 
produtos das agroindústrias familiares, suas atividades produtivas devem se transformar em atividades industriais.

A intenção deste estudo não é contrária à legalização das agroindústrias familiares. O propósito é mostrar que, por trás da legalização, da fiscalização e da execução do plano do APL Missões, ocorre uma tentativa de industrialização que desconsidera o sabor, o cheiro e a lembrança de um produto do "interior", o saber-fazer de um produto produzido artesanalmente pelas agroindústrias familiares. A imposição da lógica da economia industrial do APL para tratar e legalizar a produção familiar elimina a possibilidade de as famílias produtoras manterem sua identidade cultural e valores históricos nos seus produtos.

A tecnologia é outro ponto que apresenta contradição entre a dinâmica produtiva das agroindústrias familiares e a lógica do APL. Conforme resultados da pesquisa, a tecnologia é adquirida, predominantemente, de fornecedores de máquinas e de equipamentos. Porém, foi identificada também a presença de tecnologias desenvolvidas pelos próprios produtores, como o batedor de melado e a cortadeira de milho. Além disso, é comum encontrar nas agroindústrias familiares máquinas e equipamentos, não desenvolvidos, mas adaptados pelos próprios produtores de acordo com suas atividades.

A intenção das famílias produtoras, segundo esta pesquisa, está no sentido da incorporação da tecnologia adquirida para fins de complemento das atividades braçais e não à sua substituição. De certa forma, a incorporação da tecnologia na dinâmica produtiva das famílias torna-se um apoio ao trabalho braçal humano, não uma substituição. Essa particularidade, identificada nas visitas às agroindústrias familiares, tem relação com a produção artesanal, predominante na dinâmica produtiva.

Dessa forma, a incorporação de tecnologias ligadas à informatização, à robotização e à automação produtiva, integrada a sistemas de informações gerenciais, é inviabilizada pelo encontro com uma realidade produtiva familiar que produz artesanalmente seus produtos (PREZOTTO, 2001). Atividades produtivas sem a predominância de técnicas, mas por um conhecimento adquirido de gerações passadas, preservam a história e os valores da família, bem como a identidade regional em seus produtos. Nesse sentido, Bartra (2009) esclarece que a lógica industrial não encontra sustentação na maneira de produzir familiar. Assim, o conceito de APL, baseado na lógica industrial, não consegue ser incorporado à produção familiar.

Outra contradição envolve a comercialização dos produtos. De um lado, na dinâmica produtiva das agroindústrias familiares das Missões, a comercialização dos produtos é realizada, predominantemente, por meio da venda direta ao cliente, da feira do produtor local e pela cooperativa (quiosque). Há vendas a instituições públicas, vendas em feiras regionais e vendas externas à região, mas estas não são predominantes.

Por outro lado, o reconhecimento da existência de um APL passa por sua capacidade de exportação, ou seja, seu propósito é de formação de um polo 
produtivo que, de maneira cooperada e associada, concentra um espaço de produção em escala para atender demandas externas de consumo. Dessa forma, a geração da riqueza é reduzida ao pensamento econômico que visa à obtenção de capital externo a partir das exportações.

Essa é uma realidade distante da dinâmica produtiva das agroindústrias familiares das Missões. Dessa forma, quando a concepção do APL em relação ao propósito comercial de exportação é considerada na dinâmica produtiva familiar a contradição se materializa. Assim, a maneira como as agroindústrias familiares comercializam seus produtos diverge do objetivo comercial proposto pela lógica do APL.

Dessa forma, a origem da força de trabalho, a organização do trabalho, o conhecimento adquirido pelas famílias produtoras, a relação com os fornecedores, a forma de produção, a tecnologia e a maneira como os produtos são comercializados, formam os sete aspectos que justificam a interpretação de que o conceito de APL não é aplicável à dinâmica produtiva das agroindústrias familiares.

\section{CONSIDERAÇÕES FINAIS}

O presente estudo teve o propósito de analisar como a produção das agroindústrias familiares, na região das Missões, é influenciada pela lógica industrial do conceito de APL. No conceito de APL, está a lógica da economia neoclássica. Essa corrente de pensamento econômico se limita à obtenção de melhores resultados econômicos e à capacidade competitiva dos empreendimentos no mercado. A integração da empresa com o mercado ocorre desde a origem do suprimento, passando pela produção, pela distribuição e pelo consumidor final.

A lógica da economia de escala, intrínseca ao modelo teórico do APL, não consegue estabelecer uma relação com a dinâmica produtiva das agroindústrias familiares, pois estas apresentam baixa produção, ausência de divisão do trabalho e especialização. A autonomia das famílias produtoras com relação à organização do trabalho e à origem da matéria-prima são características que a dinâmica produtiva das agroindústrias familiares preserva ao longo do tempo. Assim, o APL somente conseguiria abarcar a produção familiar se conseguisse transformá-la em indústria. Esse é um ponto que merece maior reflexão dos produtores e atores regionais, que planejam e executam programas de incentivos e benefícios às atividades de produção familiares.

Dessa forma, a tentativa de industrialização retira a essência da atividade familiar, que não é industrial. Por isso, é importante rever os métodos de abordagem que estão sendo utilizados nos programas e planos de formação de Arranjos Produtivos Familiares, no sentido da valorização das características da 
produção familiar artesanal, que é diferente da concepção industrial do conceito de APL.

Esse é um problema identificado a partir da análise das contradições entre o conceito de APL com a dinâmica produtiva das agroindústrias familiares. $\mathrm{O}$ plano de desenvolvimento do APL das agroindústrias familiares das Missões, nesse sentido, apresenta, em toda a sua proposta, a transferência de conhecimento técnico baseado na lógica da economia industrial, deixando de considerar o saber-fazer e a identidade das famílias produtoras que optaram por manter sua produção artesanal e não industrial.

Dessa forma, a política de incentivo à criação de APLs de agroindústrias familiares deve ser revisada e aprimorada com informações que consideram a realidade da dinâmica produtiva das famílias produtoras da região. Essa é uma interpretação e recomendação deste estudo, que propõe retirar a abordagem de APL como "modelo" de desenvolvimento produtivo para o meio rural e colocar as características produtivas familiares artesanais no foco principal. Assim, essa política de incentivo às agroindústrias familiares pode oportunizar um desenvolvimento mais equitativo em relação à inclusão social e econômica das famílias produtoras.

\section{REFERÊNCIAS}

BARTRA, A. El Hombre de Hierro. Limites Sociales y Naturales del Capital. México: UACM, UAM, ÍTACA. 2009.

BECATTINI, G. Os Distritos Industriais da Itália. Empresários e empregos nos novos territórios produtivos: o caso da terceira Itália. Rio de Janeiro: DP\&A, 1999.

BRANDÃO, C. A.; COSTA, E. J. M.; ALVES, M. A. S. Construir o espaço supralocal de articulação socioprodutiva e das estratégias de desenvolvimento - os novos arranjos institucionais. In: DINIZ, C. C.; CROCCO, M. Economia Regional e Urbana - contribuições recentes. Belo Horizonte: UFMG, 2006.

BRASIL. Lei n. 11.326 de 24 de julho de 2006. Estabelece as diretrizes para a formulação da Política Nacional da Agricultura Familiar e Empreendimentos Familiares Rurais. Disponível em:

<http://www.planalto.gov.br/ccivil_03/_Ato2004-2006/2006/Lei/L11326.htm> Acesso em: 10 nov. 2014. 
CASSIOLATO, J. E., LASTRES, H. M. M. Globalização \& inovação localizada: experiências de sistemas locais no Mercosul. Brasilia: IBICT/MCT, 1999.

COSTA, A. O Papel dos APLs, das Grandes Empresas e das Cadeias Produtivas no Desenvolvimento Econômico. In: BREITBACH, Á. C. M. (org.). Os Desafios do Desenvolvimento Local. Porto Alegre: FEE, 2012.

DALLA VECCHIA, R. V. R. Arranjos Produtivos Locais como estratégia de desenvolvimento regional e local. Revista Capital Científico do Setor de Ciências Sociais Aplicadas. v. 4, n. 1 Jan/Dez. 2006.

DEPONTI, C. M. Intervenção para o desenvolvimento rural: o caso da extensão rural pública do Rio Grande do Sul. 2010. 275 f. Tese do Programa de PósGraduação em Desenvolvimento Rural - Universidade Federal do Rio Grande do Sul - UFRGS, Porto Alegre, 2010.

GAZOLLA, M. Instituições e economia dos custos de transação: aplicação de alguns elementos para a análise dos pequenos empreendimentos agroindustriais. REDES, Santa Cruz do Sul, v. 14, n. 3, 2009, p. 161-185.

GUIMARÃES, G. M.; SILVEIRA, P. R. C. Por trás da falsa homogeneidade do termo agroindústria familiar rural: indefinição conceitual e incoerências das políticas públicas. Anais do VIII Congresso da Sociedade Brasileira de Sistemas de Produção. São Luis/MA. 15p, 23 a 25 de junho de 2010.

IGLIORI, D. Economia dos Clusters Industriais e Desenvolvimento. São Paulo: Iglu, 2001.

MALUF, R. S. Mercados agroalimentares e agricultura familiar no Brasil: agregação de valor, cadeias integradas e circuitos regionais. Revista Ensaios

FEE. Porto Alegre, v. 25, n. 1, pp. 299-322, 2004.

MARSHALL, A. Princípios de Economia. São Paulo: Abril Cultural, 1982.

MATOS, M. Políticas públicas para arranjos produtivos locais: o arranjo de gemas de Teófilo Otoni - Minas Gerais. Rio de Janeiro, 2004, 121 f., Monografia (De Bacharelado na Graduação em Ciências Econômicas) - Instituto de Economia, Universidade Federal do Rio de Janeiro. 
MIOR, L. C. Agricultores familiares, agroindústrias e redes de desenvolvimento rural. Chapecó: SC, Editora Argos, 338 p., 2005.

NIERDELE, P. A.; WESZ JUNIOR, V. J. A agroindústria familiar na região das Missões: construção de autonomia e diversificação dos meios de vida. Santa Cruz do Sul, REDES. 2009. Disponível em:

<https://online.unisc.br/seer/index.php/redes/article/view/566/1431>. Acesso em: 22 mai. 2014.

PELEGRINI, G.; GAZOLLA, M. A agroindustrialização da produção como estratégia de reprodução social da agricultura familiar. In.: Cadernos do Ceam/Estudos Rurais III / Flávio Borges Botelho Filho (organizador) - Brasília: Universidade de Brasília, Centro de Estudos Avançados Multidisciplinares, Núcleo de Estudos Agrários - v. 8. n. 32, 2008.

PORTER, M. E. Vantagem competitiva das nações. Rio de Janeiro: Campus, 1990. PREZOTTO, L. L. Principais procedimentos para registrar uma pequena agroindústria. Ministério de Desenvolvimento Agrário. Secretaria da Agricultura Familiar. Brasília, janeiro de 2001.

PREZOTTO, L. L. Uma concepção de agroindústria rural de pequeno porte.

Revista de Ciências Humanas. EDUFSC. Universidade Federal de Santa Catarina. Centro de Filosofia e Ciências Humanas. Florianópolis. n. 31, abr. 2002. p.133-154.

SUZIGAN, W. et al. Clusters ou Sistemas locais de produção: mapeamento, tipologia e sugestões de políticas. Revista de Economia Política, v. 24, n. 3, p.543562, Jul. 2004.

WILKINSON, J. Sociologia econômica e o funcionamento dos mercados: inputs para analisar os micros e pequenos empreendimentos agroindustriais no Brasil. Revista Ensaios, Porto Alegre, v. 23, n. 2, p. 805-825, 2002.

ZYLBERSZTAJN, D. ; NEVES, M. F. Economia e gestão dos negócios agroalimentares: indústria de alimentos, indústria de insumos, produção agropecuária, distribuição. São Paulo: Pioneira, 2000. 
Carlos Eduardo Ruschel Anes. Doutor em Desenvolvimento Regional PPGDR/UNISC. Professor do Curso de Administração da Universidade Federal da Fronteira Sul - UFFS/Campus Cerro Largo - RS. carlos.anes@uffs.edu.br

Cidonea Machado Deponti. Professora do Programa de Pós-Graduação em Desenvolvimento Regional-PPGDR/UNISC.cidonea@unisc.br

Silvio Cezar Arend. Professor do Programa de Pós-Graduação em Desenvolvimento Regional-PPGDR/UNISC.silvio@unisc.br 